Journal of Animal and Veterinary Advances 11 (3): 375-380, 2012

ISSN: $1680-5593$

(C) Medwell Journals, 2012

\title{
Comparison of Lipogenesis Capacity of Grass Carp (Ctenopharyngodon idella) Preadipocyte from Different Anatomical Sites and Body Weight
}

\author{
Ying Li, Yang Gao, Yujuan Zhang and Youjin Hao \\ College of Life Science, Chongqing Normal University, 401331 Chongqing, P.R. China
}

\begin{abstract}
Fat cells in adipose tissue turn over throughout the life span. The objective of this study was to explore the cellular and molecular basis for regional and body weight differences in grass carp (Ctenopharyngodon idella) preadipocyte. The number of fresh isolated preadipocytes were counted from different body weight and anatomical sites using the hemocytometer and the proliferation capacity of the cells was tested by MTT assay. In addition, the differentiation capacity of cells was assessed through mRNA expression of Peroxisome Proliferator-Activated Receptor- $\gamma$ (PPAR- $\gamma$ ) and cellular Triglycerides (TG) content. The total number and proliferative capacity of visceral cells was significantly $(\mathrm{p}<0.001)$ higher compared with cells in the back subcutaneous and there was a very significant $(\mathrm{p}<0.001)$ decline in the proliferative capacity of cells with the increase of body weight. The highest TG value and mRNA level of PPAR $\gamma$ were obtained in the visceral cells from $5000 \mathrm{~g}$ fish and the TG value, mRNA level of PPAR $\gamma$ in cells increased to a greater extent with the increase of fish body weight, irrespective of the depot origin. Moreover, in the case of the same weight of fish, there was a greater differentiation degree in visceral cells than in back subcutaneous cells. In summary, preadipocyte lipogenic capacity of growing fish depends mainly on fat depot origin and significantly greater lipogenic capacity of the fish's adipose tissue is localized visceral. Furthermore, the proliferation capacity of fat cell declines with the increase of body weight and the increasing weight during the growth of healthy fish enhances the lipogenic capacity. Researchers conclude that fat cells from different regions and body weight are inherently distinct.
\end{abstract}

Key words: Anatomical sites, body weight, preadipocyte, lipogenesis capacity, grass carp, China

\section{INTRODUCTION}

Storing excess energy as neutral lipid is an evolutionarily conserved characteristic common to virtually all animals, providing a valuable energy source during periods of nutrient scarcity (Gesta et al., 2007; Schlegel and Stainier, 2007). Vertebrates are capable of storing neutral lipid in several tissues with adipose tissue serving as the primary depot. Regional distribution of fat tissue varies considerably in different species. Human adipose tissue locates mainly in the subcutaneous, mesenteric, omental and perirenal areas for rodents, most fat is in the epididymal inguinal and perirenal depots in fish, some species such as Takifugu rubripes, store triglycerides in the liver (Akiyoshi and Inoue, 2004; Kurokawa et al., 2005) whereas others such as salmonids and grass carp, store triglycerides in visceral intramuscular and subcutaneous adipocyte depots.

Adipocytes from different depots display distinctive patterns of proliferation, differentiation, gene expression, endocrine sensitivity and association with metabolic diseases (Kurokawa et al., 2005). Current knowledge of adipocyte development and physiology is largely derived from research using mammalian model systems. Human studies provide support for the hypothesis that preadipocytes and fat cells from different regions are inherently distinct. Different fat depots undergo changes at different rates with aging (Kirkland and Dobson, 1997). For example, with increasing age, retro-orbital and peripheral subcutaneous fat tend to be lost first whereas visceral fat tends to be preserved (Chumlea et al., 1989; Hughes et al., 2004). Relative to mammals, less is known about energy homeostasis in the fish, even less is known about lipogenesis in grass carp adipocyte.

Excess deposition of fat in the carcass and liver of farmed fish has increased in the last decade as a result of the rapid expansion of intensive aquaculture which affects the growth of animal and decreases the quality of fish flesh, especially in grass carp. Grass carp is one of the four major Chinese carps in the freshwater aquaculture, excess fat is stored in the form of triglycerides in visceral intramuscular and subcutaneous adipocyte depots that

Corresponding Author: Ying Li, College of Life Science, Chongqing Normal University, College Town, Huxi Campus, 401331 Chongqing, P.R. China 
strongly restricts the development of the aquaculture. However, it is not clear whether preadipocytes from different fat depots and body weight fish are distinct or not. No literature about the relationship between anatomical sites and the development of grass carp preadipocyte has been reported. Thus, we chose fish of $300,1000,5000 \mathrm{~g}$ and the visceral, back subcutaneous fat as the interest weight and sites in present study, the effects of different body weight and anatomical sites on the isolated cells number, proliferative capacity intracellular TG content and mRNA level of PPAR $y$ in fish preadipocytes were evaluated. The objective of this study was to explore the cellular and molecular basis for regional and body weight differences during development of grass carp preadipocyte. Depot and weight specific inherent mechanisms might provide a basis for studying lipogenesis and animal health in fish.

\section{MATERIALS AND METHODS}

Animals and tissue collection: Healthy grass carp of the average weight 300,1000 and $5000 \mathrm{~g}$ were bought from local fisheries. All the fish were anesthetized with metacain ( $50 \mathrm{mg} \mathrm{L}^{-1}$ ) and killed by a blow to the head. White adipose tissue that located in the visceral and back subcutaneous was collected from different body weight animals, respectively.

Grass carp preadipocytes isolation: Primary culture of grass carp preadipocytes was conducted by methods as follows. Briefly, equal amounts adipose tissue from different body weight and anatomical sites fish was rinsed with KRB (Krebs Ringer Bicarbonate, containing 3\% BSA, $10 \mathrm{mM}$ glucose, $50 \mathrm{U}$ penicillin $\mathrm{mL}^{-1}$ and streptomycin) buffer. The tissue was cut with scissors into approximately $1 \mathrm{~mm}^{3}$ sections and then incubated in a digestion buffer comprised of Dulbecco's Modified Eagle Medium/F12 (DMEM/F12, a 50:50 mixture of DMEM/F12, Gibco), $100 \mathrm{mM}$ Hepes, $20 \mathrm{~g} \mathrm{~L}^{-1}$ Bovine Serum Albumin (BSA, Sigma), $\mathrm{pH} 7.4$, containing $1 \mathrm{~g} \mathrm{~L}^{-1}$ collagenase (Type I, Gibco). A 5-fold excess of digestion buffer (room temperature, excluding collagenase) was added to the digestion flask after incubating for $60 \mathrm{~min}$ at $28^{\circ} \mathrm{C}$ in a shaking water bath. To remove undigested tissue and large cell aggregates, flask contents were mixed and filtered through $200 \mu \mathrm{m}$ nylon mesh filter. The filtered cells were centrifuged at $800 \times \mathrm{g}$ for $5 \mathrm{~min}$ to separate the floating adipocytes from the pellet of stromal-vascular cells. The stromal-vascular cells were then incubated with erythrocyte lysis buffer $\left(0.154 \mathrm{M} \mathrm{NH}_{4} \mathrm{Cl}, 10 \mathrm{mM} \mathrm{KHCO}_{3}\right.$, $0.1 \mathrm{mMEDTA}$ ) at room temperature for $10 \mathrm{~min}$ followed by centrifugation. The stromal-vascular cell pellet was washed twice with DMEM/F12 medium supplemented with $15 \mathrm{mM} \mathrm{NaHCO}$, $50 \mathrm{U}$ penicillin $\mathrm{mL}^{-1}$ and streptomycin. After washing, the cells were resuspended in DMEM/F12 medium containing 10\% Fetal Bovine Serum (FBS vol/vol, Sigma).

Cell counting and primary culture: The cells were counted from different body weight and anatomical sites using the hemocytometer. Finally, aliquots were seeded in culture flasks, 96, 24 or 6 well plates at a density of $3 \times 10^{4}$ cells $\mathrm{cm}^{-2}$ and maintained at $28^{\circ} \mathrm{C}$ in a humidified $5 \% \mathrm{CO}_{2}$ atmosphere. The medium was changed every other day.

MTT assay: At 8 days, cell proliferation was evaluated by MTT assay according to the methods of (Pieters et al., 1990). Briefly, an MTT stock solution (Sigma, $5 \mathrm{mg}$ of MTT $\mathrm{mL}^{-1}$ of Phosphate-Buffered Saline, PBS) was sterilized and kept for no $>2$ weeks at $4^{\circ} \mathrm{C}$. To start the coloring reaction, stock solution was added to growing cultures (final concentration, $0.5 \mathrm{mg} \mathrm{mL}^{-1}$ ). The mixture was incubated for $4 \mathrm{~h}$ at $28^{\circ} \mathrm{C}$. Blue crystals developed over the mitochondria in living cells. After $4 \mathrm{~h}$, formazan crystals were dissolved with $100 \mu \mathrm{L}$ of $0.04 \mathrm{M} \mathrm{HCl}$ isopropyl alcohol (acid isopropanol) on a shaker (160 rpm at $20^{\circ} \mathrm{C}$ ) for $10 \mathrm{~min}$. The Optical Density (OD) of the wells was measured at a wavelength of $340 \mathrm{~nm}$ with a microplate reader. The OD value of each well containing medium but no cells was subtracted from the OD value of wells containing cells and medium. All assays were replicated six times.

Cellular TG content analysis: At days 20 of the culture period, cultured cells on 24 well plates were washed 3 times with PBS then cells were harvested in $0.5 \mathrm{~mL}$ of extraction buffer containing $50 \mathrm{mM}$ Tris ( $\mathrm{pH} 7.5$ ), $1 \mathrm{mM}$ EDTA and $1 \mathrm{mM}$ mercaptoethanol at $4^{\circ} \mathrm{C}$ after which the extraction was placed in an ice bath and sonicated at $0^{\circ} \mathrm{C}$. The suspension was divided into several aliquots. An aliquot was measured using a kit for TG (Zhongsheng Peking Bio-Technology and Science Inc, China).

Extraction total RNA and RT-PCR analysis: At days 20 of the culture period, total cellular RNA was extracted from primary cultured preadipocytes by using TRIZOL Reagent (Fermentas Life Science) following the manufacturer's protocol. After DNase treatment, RNA quality and quantification were measured by electrophoresis and spectrophotometry at 260 and $280 \mathrm{~nm}$, respectively (Peterson, 1977).

Reverse transcription was performed to synthesize cDNA with a first strand cDNA Synthesis kit (Fermentas Life Science). The synthesized cDNA were then amplified by PCR using paired sense and antisense primers of 
Table 1: Parameters of primer pairs

\begin{tabular}{lllc}
\hline Genes & Accession no. & \multicolumn{1}{c}{ Primer sequence } & Source of primers \\
\hline$P P A R \gamma$ & EU847421 & S:5TTGGTCAGGGGGAAATACT3' & Grass carp \\
& & A:5TCCTCCACAGTTGGCGA3' \\
$\beta$-actin & DQ311096 & A:5'CAGAGCTTCTCCTTGATGTC3' & 438 \\
& & S:5'GATATGGAGAAGATCTGGCA 3' & Grass carp \\
\hline
\end{tabular}

$\mathrm{S}=$ Sense primer; $\mathrm{A}=$ Antisense primer

$\beta$-actin (as the internal control) and PPAR $\gamma$ (Table 1) in the same sample according to the methods of (Peterson, 1977). The PCR conditions included an initial denaturation at $95^{\circ} \mathrm{C}$ for $10 \mathrm{~min}$ followed by 30 cycles of $95^{\circ} \mathrm{C}$ for $1 \mathrm{~min}, 55.5^{\circ} \mathrm{C}$ for $1 \mathrm{~min}$ and $72^{\circ} \mathrm{C}$ for $1 \mathrm{~min}$ and a final extension step at $72^{\circ} \mathrm{C}$ for $10 \mathrm{~min}$. The amplified fragments were separated with electrophoresis by using $1 \%$ agarose gel.

Images of the RT-PCR ethidium bromide-stained agarose gels were acquired with a CCD camera and quantification of the bands was performed using Dolphin1D software (Wealtec International Ltd.). Band intensity was expressed as relative absorbance units. The ratio of band intensity between the mRNA of interest and $\beta$-actin was calculated to normalize for initial variations in sample concentration.

Statistical analysis: A single batch of fish preadipocytes from an individual fish was used for each replicate. Each treatment within an experiment was replicated 6 times. For the cell counting, MTT assay, TG content evaluation and gene expression detection were performed with three replicates. Treatments were compared by ANOVA (SPSS 13.0). Differences were considered statistically significant at $\mathrm{p}<0.05$. Data were presented as means (SD) calculated from three replicates.

\section{RESULTS AND DISCUSSION}

Effect of anatomic sites and body weight on the fresh isolated cell number and proliferation capacity: The cells were isolated from equal amounts visceral and back subcutaneous fat tissue in the different body weight subjects. The results of fresh isolated preadipocytes numbers and proliferation capacity from each group were shown in Fig. 1 and 2. In equal amounts adipose tissue, the cells number of preadipocytes isolated from different weight fish in the visceral ranged $5.4567 \times 10^{4}-1.9567 \times 10^{4}$ compared to a 4.9367-2.9433 varied rate in the back subcutaneous. Likewise, the proliferative capacity of visceral cells was also significantly $(p<0.001)$ higher compared with cells in the back subcutaneous and there was a very significant $(\mathrm{p}<0.001)$ decline in the proliferation capacity of cells with weighing when compared with the $500 \mathrm{~g}$ fish.

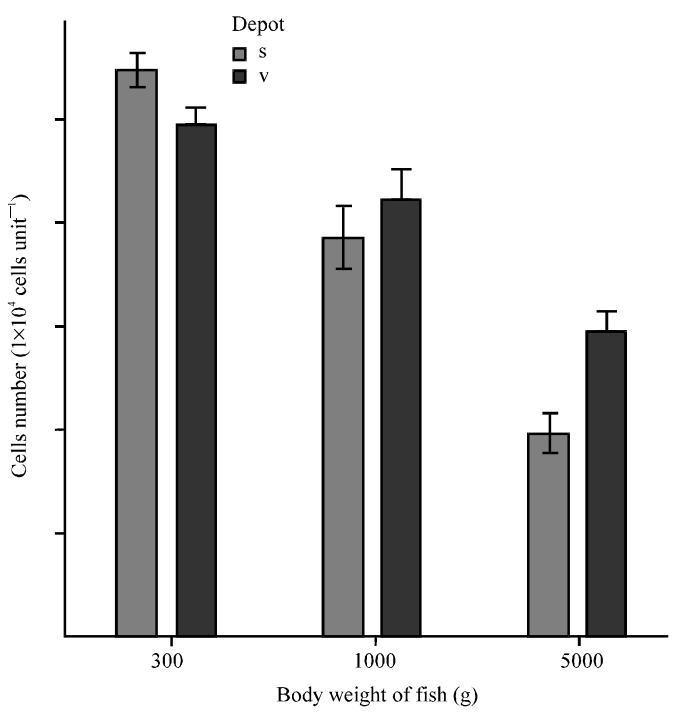

Fig. 1: Effect of anatomic sites and body weight on the fresh isolated cells number. Columns and error bars mean (SD)

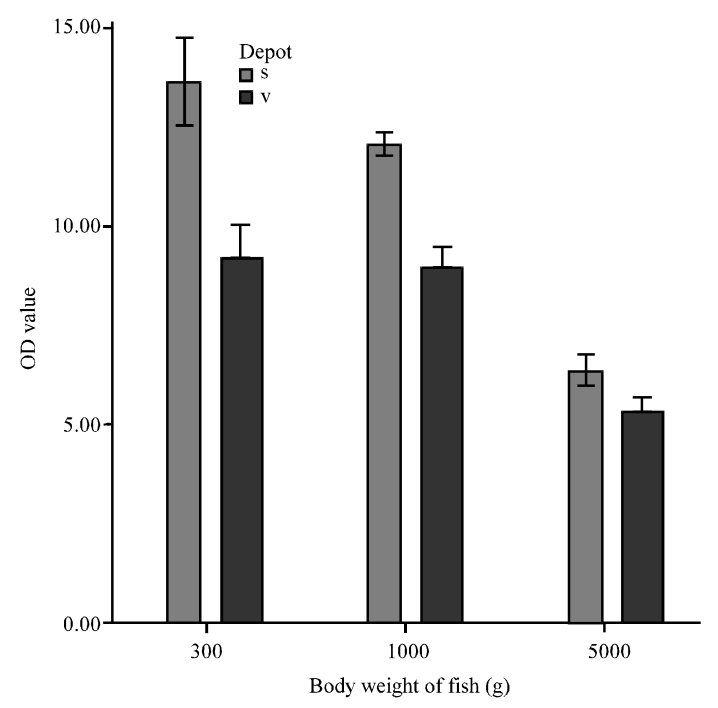

Fig. 2: Proliferation capacity of grass carp adipocyte by MTT assay. Columns and error bars mean (SD)

Fat mass and fat tissue distribution change dramatically with aging. The distribution of white adipose tissue not only varies considerably between species but also between individuals of the same species. Fat cells in 
adipose tissue turn over throughout the life span with new fat cells developing from preadipocytes which account for $15-50 \%$ of the cells in fat tissue, give rise to new fat cells throughout life.

In present study, preadipocyte existed in the visceral and back subcutaneous of fish, regardless of body weight and depots and the potential adipogenesis capacity of visceral cells was also significantly higher compared with back subcutaneous cells. Moreover, the cells number exhibited some degree of decline during fish growth and the extent of decrease was greater in the visceral compared with the back subcutaneous. In humans, variations of white fat distribution have gained considerable interest due to their association with metabolic disorders (Fruhbeck et al., 2001). In rat, preadipocytes cultured from perirenal depots were shown to be capable of more extensive replication and differentiation in vitro and in vivo than preadipocytes from epididymal depots (Kirkland et al., 1990, 1996). Another experiment demonstrated that preadipocytes isolated from young and old rats, cultured in parallel under identical conditions, retain age-dependent cell dynamic characteristics indicating the involvement of cell-specific inherent mechanisms in these changes (Karagiannides et al., 2001, 2006). It is well known that there is a positive correlation between the body weight and age during the development of animal and the body weight will increase with ageing. In the study, the subjects were growing and healthy. Thus, we have demonstrated the results here that are consistent with studies in rat and humans and these findings all support the hypothesis that fat depot origin and body weight affect isolated preadipocytes numbers and proliferation capacity in individual fish.

\section{Preadipocyte differentiation depends mainly on fat depot} origin: As described preadipocytes from different weight and sites differed in replicative behavior, it was of interest to determine whether these cells also displayed differences in capacity for differentiation. In present study, after cells had been cultured for 20 days, the differentiation capacity of cells was assessed through TG content (Fig. 3) and mRNA expression of PPAR y (Fig. 4). As expected, significant differences were found in the TG content of cells among any two weight group in the visceral fat depot. In addition, we found TG content of cells was significantly greater $(p<0.0001)$ in the visceral than in the back subcutaneous depot, regardless of actual body weight. However, despite less change extent of $O D$ value was in the back subcutaneous depot compared with visceral fat depot, there was a significant $(\mathrm{p}<0.05)$ increase

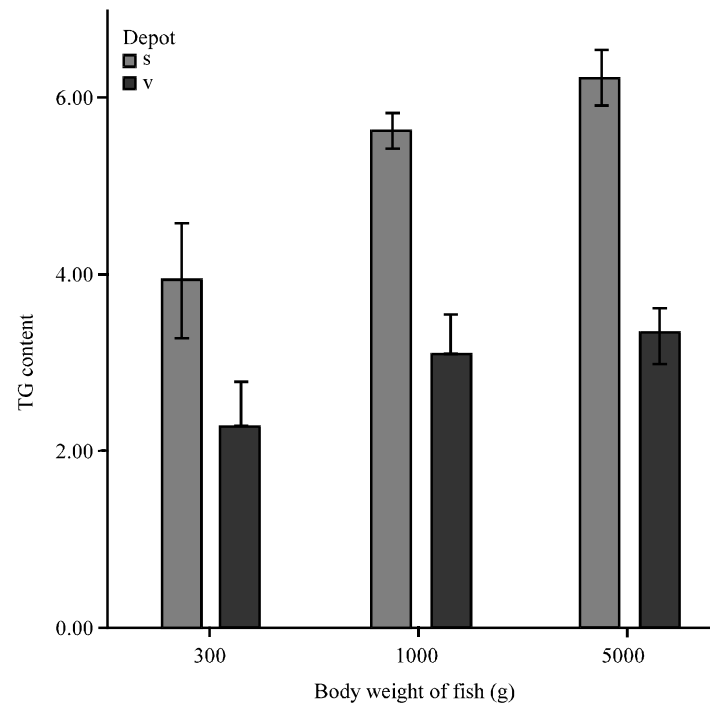

Fig. 3: TG content of cells in different anatomic site and body weight fish. Columns and error bars mean (SD)
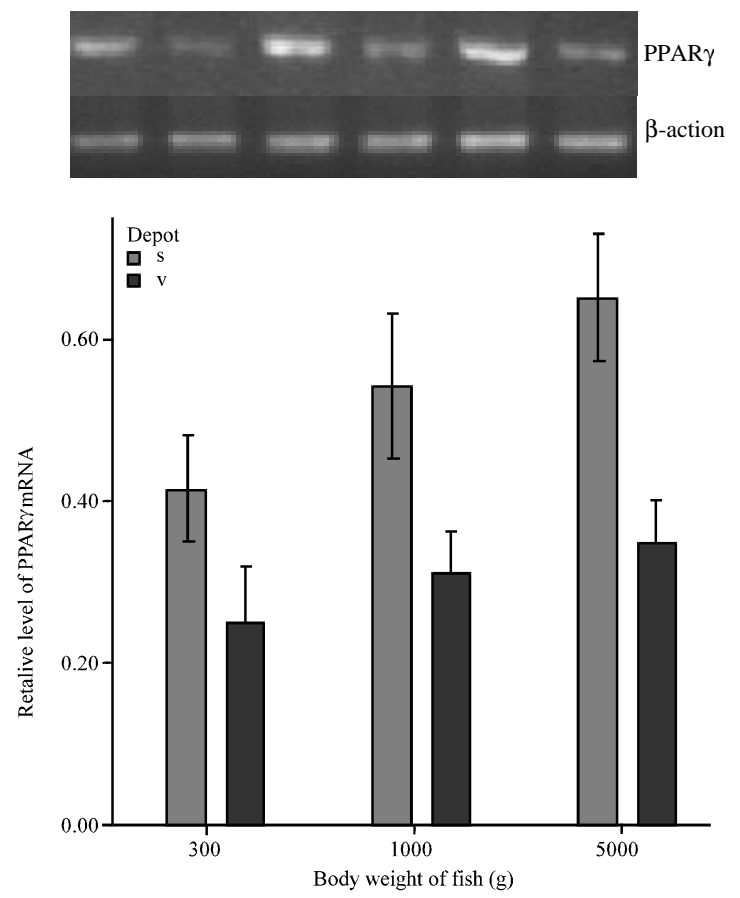

Fig. 4: PPAR $\gamma$ mRNA levels in different different anatomic site and body weight fish. Columns and error bars mean (SD)

in the values of $\mathrm{OD}$ among the body weight of 1000 and $5000 \mathrm{~g}$ when compared with the $300 \mathrm{~g}$. The PPAR $\gamma$ expression patterns were consistent with the analysis regarding TG content. Adipose tissue is the most important storage organ for $\mathrm{TG}$ and $\mathrm{TG}$ is stored in 
intracellular lipid droplets of adipocytes. Since, adipocyte differentiation and maintenance of the fat cell phenotype are dependent on the transcription factors, PPAR $\gamma$ is the master regulator of adipocyte gene transcription (Brandebourg and $\mathrm{Hu}, 2005$ ), changes that occur with body weight in adipocytes may be a consequence of changes in expression of the key adipogenic transcription factors. In this study, not only do preadipocytes isolated from visceral and back subcutaneous depots maintain depot and weight-specific dynamic properties, they also exhibit unique lipogenesis capacity. Visceral cells had a higher adipogenic capacity compared with back subcutaneous cells as indicated by lipid accumulation. The highest TG value was obtained in the visceral cells from $5000 \mathrm{~g}$ fish which exhibited 1.58-fold greater TG content compared with the $500 \mathrm{~g}$ fish. In the study, with the increase of fish body weight, the expression level of PPAR $\gamma$ in cells increased to a greater extent, irrespective of the depot origin. Moreover in the case of the same weight of fish, there was a greater level of PPARy expression in visceral cells than in back subcutaneous cells and the capacity of preadipocytes to become fully functional mature adipocytes increases with body weight. In human preadipocyte studies where regional differences were found, subcutaneous preadipocytes tended to have greater capacity for replication, lipid accumulation, GPDH activity, expression of $\mathrm{aP} 2, \mathrm{C} / \mathrm{EBP} \alpha$ and $\operatorname{PPAR} \gamma$ and responsiveness to thiazolidinediones than visceral preadipocytes (Tchkonia et al., 2002). In another study, genome-wide expression profiles of primary preadipocytes from human abdominal subcutaneous, mesenteric and omental fat tissue differed with respect to gene signatures (Tchkonia et al., 2007). In rat, gene expression was profiled in preadipocytes cultured from epididymal and perirenal depots of young and old rats. About $8.4 \%$ of probe sets differed significantly between depots particularly developmental genes and age-related changes were greater in perirenal than epididymal preadipocytes (Cartwright et al., 2010). Thus, in the study, TG value and mRNA level of PPAR in cells support the contention that preadipocytes from different fat depots are distinct, preadipocyte differentiation depends mainly on fat depot origin and significantly greater lipogenic capacity of the fish's adipose tissue was localized visceral.

\section{CONCLUSION}

In this study, preadipocyte lipogenic capacity of growing fish depends mainly on fat depot origin and significantly greater lipogenic capacity of the fish's adipose tissue is localized visceral. Furthermore, the proliferation capacity of fat cell declines with the increase of body weight and the increasing weight during the growth of healthy fish enhances the lipogenic capacity. Based on this study, researchers suggested that depot and body weight specific characteristics inherent to preadipocytes contributed to changes in growth and function of adipose tissue with body weight in fish and fat cells from different regions were inherently distinct.

\section{ACKNOWLEDGEMENT}

This research was sponsored by National Natural Science Foundation of China (30800843).

\section{REFERENCES}

Akiyoshi, H. and A. Inoue, 2004. Comparative histological study of teleost livers in relation to phylogeny. Zool. Sci., 21: 841-850.

Brandebourg, T.D. and C.Y. Hu, 2005. Regulation of differentiating pig preadipocytes by retinoic acid. J. Anim. Sci., 83: 98-108.

Cartwright, M.J., K. Schlauch, M.E. Lenburg, T. Tchkonia and T. Pirtskhalava et al., 2010. Aging, depot origin and preadipocyte gene expression. J. Gerontol. A: Biol. Sci. Med. Sci., 65: 242-251.

Chumlea, W.C., R.L. Rhyne, P.J. Garry and W.C. Hunt, 1989. Changes in anthropometric indices of body composition with age in a healthy elderly population. Am. J. Hum. Biol., 1: 457-462.

Fruhbeck, G., J. Gomez-Ambrosi, F.J. Muruzabal and M.A. Burrell, 2001. The adipocyte: A model for integration of endocrine and metabolic signaling in energy metabolism regulation. Am. J. Physiol. Endocrinol. Metab., 280: E827-E847.

Gesta, S., Y.H. Tseng and C.R. Kahn, 2007. Developmental origin of fat: Tracking obesity to its source. Cell, 131: 242-256.

Hughes, V.A., R. Roubenoff, M. Wood, W.R. Frontera and W.J. Evans, 2004. Anthropometric assessment of 10 -y changes in body composition in the elderly. Am. J. Clin. Nutr., 80: 475-482.

Karagiannides, I., T. Tchkonia, D.E. Dobson, C.M. Steppan and P. Cummins et al., 2001. Altered expression of $\mathrm{C} / \mathrm{EBP}$ family members results in decreased adipogenesis with aging. Am. J. Physiol., 280: R1772-R1780.

Karagiannides, I., T. Thomou, T. Tchkonia, T. Pirtskhalava and K.E. Kypreos et al., 2006. Increased CUG triplet repeat-binding protein-1 predisposes to impaired adipogenesis with aging. $\mathrm{J}$. Biol. Chem., 281: 23025-23033. 
Kirkland, J.L. and D.E. Dobson, 1997. Preadipocyte function and aging: Links between age-related changes in cell dynamics and altered fat cell function. J. Am. Geriatr. Soc., 45: 959-967.

Kirkland, J.L., C.H. Hollenberg and W.S. Gillon, 1990. Age, anatomic site and the replication and differentiation of adipocyte precursors. Am. J. Physiol., 258: C206-C210.

Kirkland, J.L., C.H. Hollenberg and W.S. Gillon, 1996. Effects of fat depot site on differentiation-dependent gene expression in rat preadipocytes. Int J. Obesity Relat. Metab. Disorders, 20: S102-S107.

Kurokawa, T., S. Uji and T. Suzuki, 2005. Identification of cDNA coding for a homologue to mammalian leptin from pufferfish. Takifugu Rubripes Peptides, 26: 745-750.

Peterson, G.L., 1977. A simplification of the protein assay method of Lowry, which is more generally applicable. Anal. Biochem., 83: 346-356.
Pieters, R., A.H. Loonen, D.R. Huismans, G.J. Broekema and M.W.J. Dirven et al., 1990. In vitro drug sensitivity of cells from children with leukemia using the MTT assay with improved culture conditions. Blood, 76: 2327-2336.

Schlegel, A. and D.Y. Stainier, 2007. Lessons from lower organisms: What worms, flies and zebra fish can teach us about human energy metabolism. PLoS Genet., Vol. 3 10.1371/journal.pgen.0030199

Tchkonia, T., M. Lenburg, T. Thomou, N. Giorgadze and G. Frampton et al., 2007. Identification of depotspecific human fat cell progenitors through distinct expression profiles and developmental gene patterns. Am. J. Physiol. Endocrinol. Metab., 292: E298-E307. Tchkonia, T., N. Giorgadze, T. Pirtskhalava, Y. Tchoukalova and I. Karagiannides et al., 2002. Fat depot origin affects adipogenesis in primary cultured and cloned human preadipocytes. Am. J. Physiol. Regul. Integr. Comp. Physiol., 282: R1286-R1296. 